\title{
Modeling and real time digital simulation of microgrids for campuses Malta and Jordan based on multiple distributed energy resources
}

\author{
Sidahmed Khiat ${ }^{1}$, Abdelkader Chaker ${ }^{2}$, Lazaros Zacharia ${ }^{3}$, Ahmed Onen ${ }^{4}$ \\ ${ }^{1,2}$ SCAMRE Laboratory, Departement of Electrical Engineering, National Polytechnic School of Oran - Maurice Audin \\ (ENPO-MA), Oran, Algeria \\ ${ }^{3}$ KIOS Research and Innovation Center of Excellence, University of Cyprus, Nicosia, Cyprus \\ ${ }^{4}$ Department of Electrical and Electronics Engineering, Abdullah Gul University, Kayseri, Turkey
}

\begin{abstract}
Article Info
Article history:

Received Jun 15, 2020

Revised Aug 7, 2020

Accepted Aug 21, 2020

Keywords:

Microgrid

Modeling

Real-time digital simulation

RT-LAB platform

ABSTRACT

This paper presents the modeling and real-time digital simulation of two microgrids: the malta college of arts, science and technology (MCAST) and the german jordan university (GJU). The aim is to provide an overview of future microgrid situation and capabilities with the benefits of integrating renewable energy sources (RES), such as photovoltaic panels, diesel generators and energy storage systems for projects on both campuses. The significance of this work starts with the fact that real measurements were used from the two pilots, obtained by measuring the real physical systems. These measures were used to plan different solutions regarding RES and energy storage system (ESS) topologies and sizes. Also, the demand curves for the real microgrids of MCAST and GJU have been parameterized, which may serve as a test bed for other studies in this area. Based on actual data collected from the two pilots, a real-time digital simulation is performed using an RT-LAB platform. The results obtained by this tool allow the microgrid manager to have a very accurate vision of the facility operation, in terms of power flow and default responses. Several scenarios are studied, extracting valuable insight for implementing both projects in the future. Eventually, the proposed models would be a blueprint for training and research purposes in the microgrid field.
\end{abstract}

This is an open access article under the CC BY-SA license.

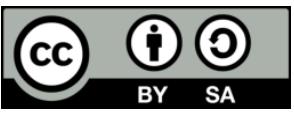

\section{Corresponding Author:}

Sidahmed Khiat

SCAMRE Laboratory

Departement of Electrical Engineering

National Polytechnic School of Oran - Maurice Audin (ENPO-MA)

B.P. 1523 El M'Naouer 31000, Oran, Algeria

Email: sidahmed.khiat@enp-oran.dz

\section{INTRODUCTION}

Electrical energy is a key element in the social and economic growth of nations. The traditional electrical power system represents a complete ecosystem that supports socio-economic development through the provision of a secure and reliable supply of electricity at a minimum cost to all sectors. The future of electrical systems will be much more focused on small-scale generation and distribution where end-users will be active participants with localized energy management systems that can interact on a free energy market in a number of countries. Regulatory reforms have been made to support this transformation by allowing endusers to invest in RES. Thus, a new concept of power supply networks emerges to generate, distribute, and regulate the power flow on national, regional and local scale [1]. 
In this context, microgrids are modern power supply networks, which are small-scale versions of the centralized electricity systems, and are designed to provide power for small communities. Microgrids consist of distributed energy resources (DERs), ESS and controllable loads, which can either be connected to the grid (grid-connected operation) or be isolated from it (islanded operation). This crucial functionality provides the means to increase the power quality of supply and improve local reliability. In addition, low investment costs, reduced carbon emissions and energy losses can also contribute to the benefits, as well as robustness and resilience, key features of microgrid systems, further enhancing their operation. Microgrids have been technically investigated in the several review papers [2-4].

Generally, the proposed architectures for microgrids are mainly three: AC-microgrids, DCmicrogrids, and hybrid AC/DC microgrids [3-5]. While AC microgrids have more capacity, controllability and flexibility, DC microgrids have higher system efficiency, lower cost and system size because of the absence of the DC/AC inverters. Hybrid AC/DC architecture has advantages of both AC and DC microgrid architectures, such as minimum number of interface elements, easier integration of DERs, reduced conversion stages, energy losses and total costs, and higher reliability [6-9].

Microgrids generate, distribute and regulate the power flow to consumers on a local dimension. energy management systems (EMS) are employed to undertake the essential role of providing stable, reliable and sustainable microgrid operation, as well as other goals such as minimizing costs and fuel consumption [10-14]. EMS for microgrids can be divided into 2 configurations: centralized [15-17] and decentralized [18-21].

Despite the many advantages of microgrids, there are still major challenges/barriers to address when connecting microgrid systems to the distribution grid [22, 23]. Penetration of RES to the grid can cause serious problems because of their intermittent and volatile nature [24]. Moreover, because of the various and heterogeneous components used in large-scale microgrids, compatibility problems between components are often observed. Protection issues are also one of the significant challenges. The characteristics of protection schemes in microgrids are different from those of traditional distribution systems, where differences in the configuration applied are also identified according to the operation mode (grid-connected or islanded) [25-29].

Taking into consideration all of the above it is evident that microgrids are an area of extensive research, and standardized solutions that can be easily adapted to all kinds of local conditions of demand requirements and resource availability do not exist yet. Particularly over the last years, there is an increasing interest amongst the research society to explore and exploit the benefits and overcome the barriers for integrating microgrids, especially in the context of the smart grid (SG). Due to this reason, higher education university main campuses at MCAST (Malta) and GJU (Jordan) are chosen as pilots for the development of microgrids, which can be utilized as living laboratories for research purposes [30].

To avoid these challenges in real site implementation, real time digital simulations are used to test the control design, investigate components and its compatibility with each other and provide an opportunity to make changes in the system before the assembly or start-up process. The various real-time testing approaches that are used for microgrids are mainly three: purely software real-time digital simulation (RTS), hardware in the loop (HIL) and power HIL (PHIL) [31, 32]. In the pure software RTS, there is no interaction with any hardware and the whole system is operated in the digital simulation environment. On the contrary, both software and hardware are needed for HIL. Thus, results obtained from the simulator are more close to real site results. On the other hand, PHIL operates sending or absorbing the power required by the devices under test (DUT). When doing this, power amplifiers are needed between the actual system and the real-time simulator [33, 34]. There are several companies serving the real-time simulator market such as OPAL-RT Technologies [35], RTDS Technologies [36], Typhoon HIL [37] and National Instruments [38, 39]. In this study, we consider a pilot microgrid design that consists of photovoltaics, standby diesel generators, and backup ESS. It is analyzed both in grid-connected and islanded operation.

The design of the microgrids performed on the OPAL-RT / RT-LAB platform. The main contribution of this paper is to present the modeling of the two microgrid systems under various scenarios and to simulate in real-time the MCAST and GJU pilot microgrids building upon existing data from each one Our digital simulation in real time demonstrate the robust performance of the proposed system [40]. The presented work is part of the multi-stakeholder collaborative project "3DMicroGrid", financed through the ERANETMED initiative of the EU. Its objective is to propose new microgrid models with enhanced performance. This is achieved by innovative control methodologies which ensure stable and smooth operation, either in gridconnected or islanded mode, maximize RES integration and improve reliability and power quality.

The rest of the paper is organized as follows: Section 2 explains the architectures of the proposed model, including MCAST and GJU pilots. Section 3 describes their component models. Real time digital simulation is described in Section 4. The results and analyses of the scenarios according to the real-time digital simulation of the MCAST and GJU microgrids are discussed in Section 5. Finally, Section 6 presents the conclusions. 


\section{MCAST AND GJU MICROGRID PILOTS DESCRIPTION}

Towards better understanding the examined scenarios and configurations, this section presents in detail the topologies of the two pilots. As already stated, the designed microgrids are based on real-life premises that have been designed towards operating as fully functional microgrids. The simulated scenarios are synthesized from real-data extracted from the actual infrastructure.

Business scenarios and technical use cases are developed to cover basic microgrid functionalities for the MCAST and GJU pilot sites. The aim is to deliver a hybrid control architecture that incorporates both centralized and decentralized principles in a multi-agent scheme [41,42]. The conceptual architecture, based on 3-level hierarchical control requirements, is thoroughly modelled. Then, different scenarios are executed in real-time digital simulation.

\subsection{MCAST microgrid pilot description}

The pilot microgrid will cover the part of MCAST campus which consists of three buildings (D, F, and J) and an underground car park as shown in Figure 1. The current electrical network of the MCAST pilot area consists of two substations (SS1 for J and SS2 for D and F). Every substation is separated into two parts: one for the high voltage (HV) switchgear and transformers and another one for the low voltage (LV) switchgear [30, 40].

There are $63.24 \mathrm{kWp}$ PV systems installed on the three buildings (D, F and J). So far, a $21.12 \mathrm{kWp}$ PV is connected to the LV system in Block J (SS1). Another two facilities with $21.12 \mathrm{kWp}$ and $21 \mathrm{kWp}$, located on top of Block D and Block F, respectively, will be connected very soon to SS2. Figure 2 displays the microgrid pilot.

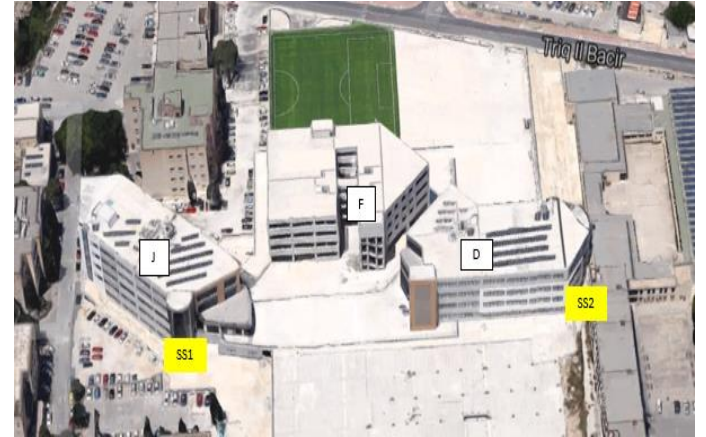

Figure 1. Aerial view of MCAST buildings being proposed

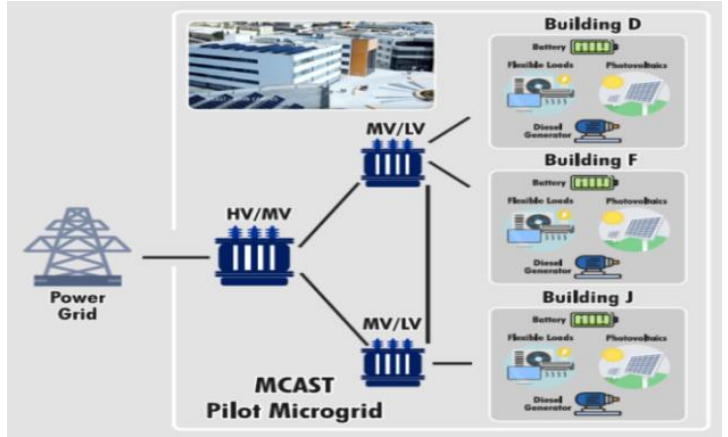

Figure 2. MCAST campus case study- microgrid pilot

The building management system (BMS) (is developed using Trend 963 Server Package using Trend IQ4E controller) for the pilot buildings is already collecting energy data. To support real-time microgrid operation, the infrastructure has already been designed and currently being deployed to support open-protocol gateways, which are in turn 'linked' to the main controller. This incorporates standard protocols and drivers, such as Modbus (both RTU and TCP/IP), Bacnet IP and Lon, all of which will be required to enable interaction between systems $[40,41]$. Through these interfaces, data is gathered from each system, as shown in Figure 3. Additional data can be added in the future as necessary.

Every building is equipped with a BMS to control the loads (HVAC, lights, etc.) in floor level but not all of them log the data. In order to solve this problem, the loads are categorized according to their functionality into four types: offices, classrooms, labs and services. Then, the consumption per $\mathrm{m}^{2}$ of each type is calculated and aggregated values for each building are extracted to create the various load profiles.

\subsection{GJU microgrid pilot description}

The microgrid pilot will cover the whole campus of GJU which consists of thirteen buildings plus another three under construction. The main station contains two 33/11 KV transformers. Every one of which feeds three 11/0.4 KV transformers located around the campus feeding all the buildings. In total, there are six transformers in a loop configuration around the campus to increase the reliability of the system, see Figure 4.

The microgridis expected to use four sources of electricity (Utility grid, PV system, diesel generator and ESS) in order to meet the demand in the campus while achieving high reliability and low operating cost. Figure 5 shows the GJU campus microgrid pilot [41-43]. Every building is equipped with a BMS to control the loads (HVAC, lights, etc.) in floor level but not all of them log the data. In order to solve this problem, the loads are categorized according to their functionality into four types: offices, classrooms, labs and services. Then, the consumption per $\mathrm{m}^{2}$ of each type is calculated and aggregated values for each building are extracted to create the various load profiles. 


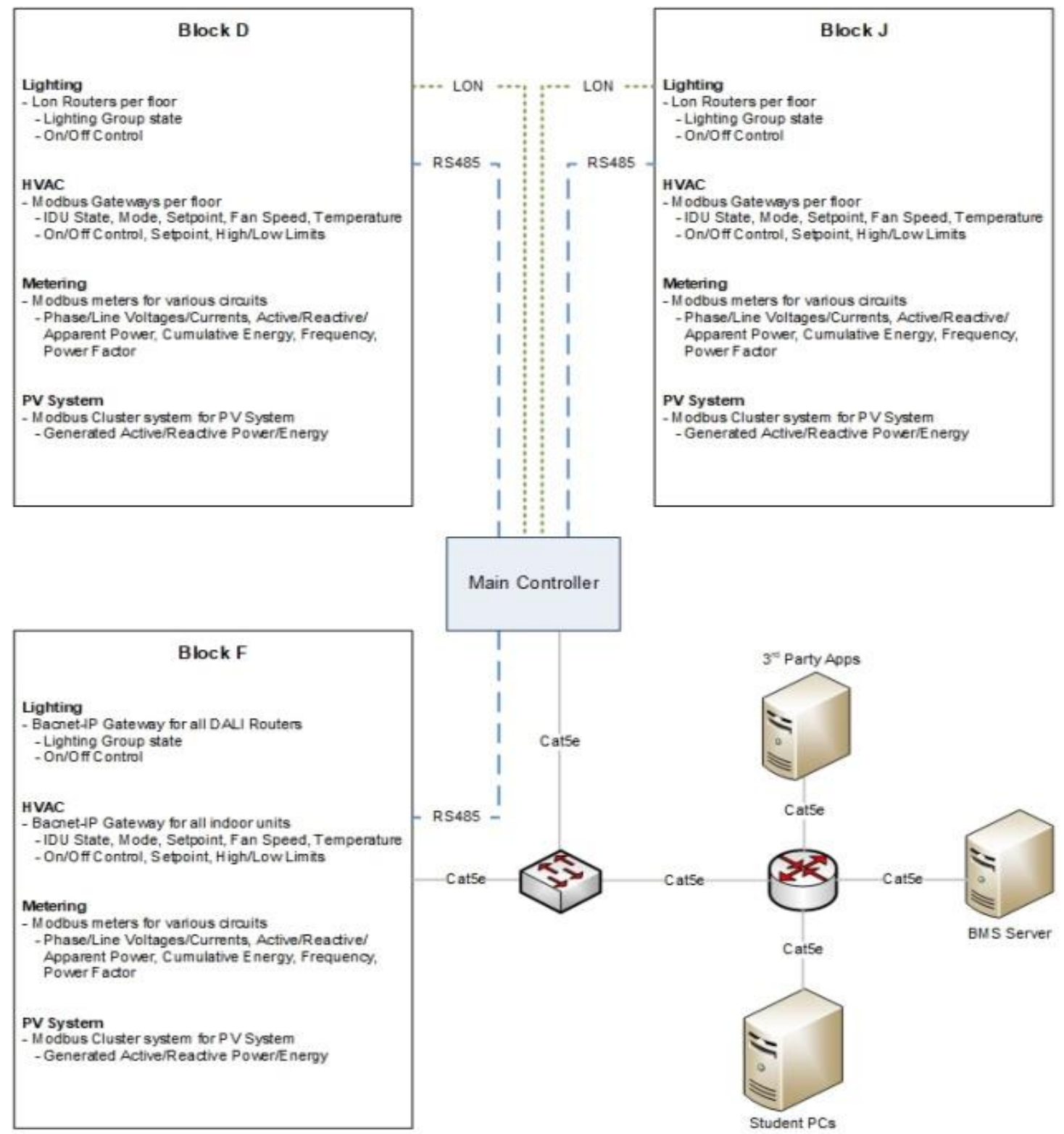

Figure 3. Building management system overview

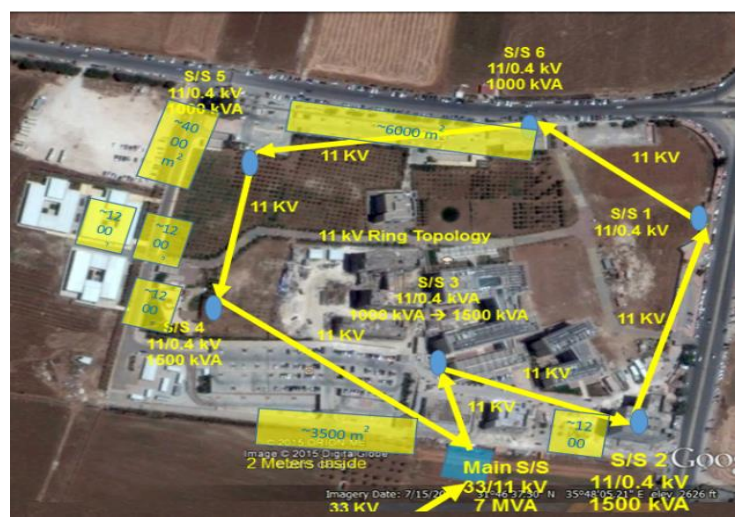

Figure 4. Distribution of GJU buildings and electrical network

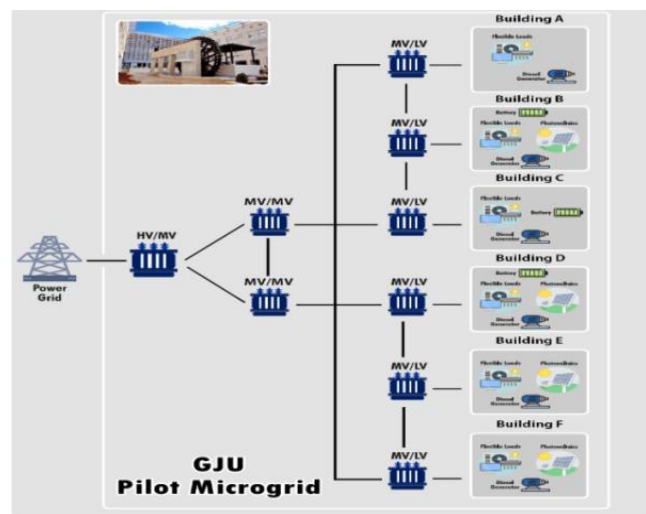

Figure 5. GJU campus microgrid pilot 


\section{MODELING MICROGRID SYSTEMS COMPONENTS}

In order to be able to model the microgrid and perform a digital simulation in real time, we first modeled the microgrid components such as: a) building model, b) PV system model, c) ESS model, and d) diesel generator model, for both MCAST and GJU pilot microgrids, in discrete time EMT simulation models [44-46].

\subsection{Building model}

The building model is a Three-phase load model (4-wire) and depends on the seasonal load profiles, Figure 6. In this block, typical load profiles are used and must be updated according to the MCAST and GJU measurements [41-46]. The load models are modeled as ideal current sources where the absorbs current ensures that follows the load profile consumption according to the existing voltage conditions as shown in Figure 6.
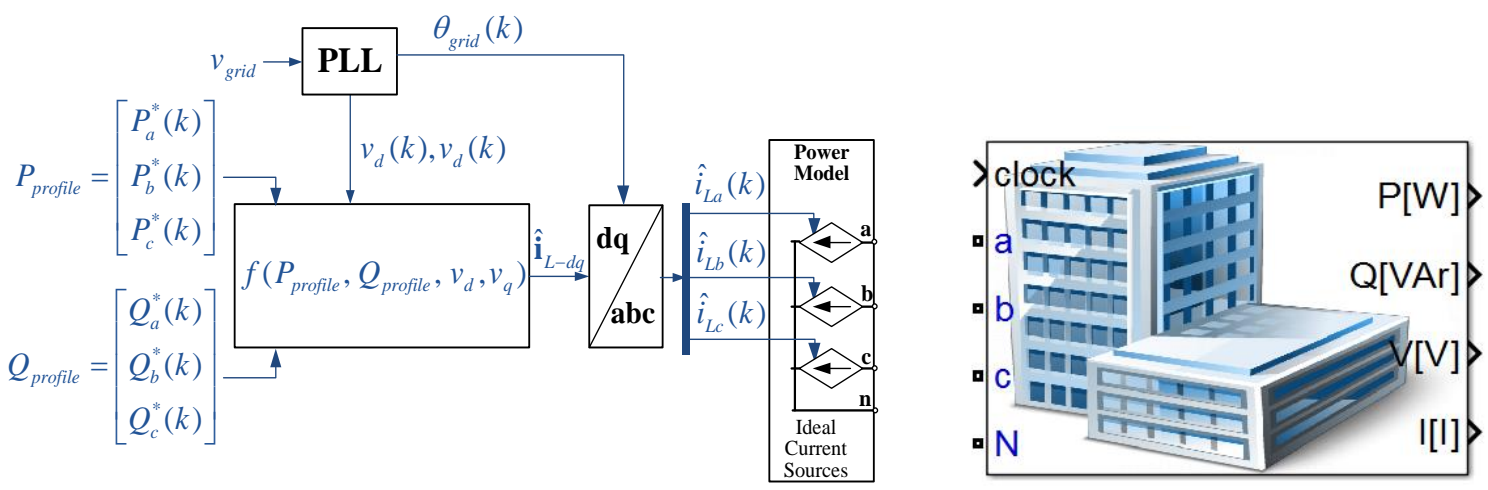

Figure 6. Building model - controllable and uncontrollable loads

\subsection{PV model}

The PV system model is built using Matlab/Simulink and it contains a 3-wire interconnection. The production of power (PPV) depends on the solar irradiation for $24 \mathrm{~h}$ (every 1s), the temperature of the environment and configuration of the PV panels. To enable the appropriate operation of the PV system, an advanced model for the grid side converter (GSC) has been developed. As shown in Figure 7 the GSC is managed by its controller based on a synchronization method, a PQ controller, a current controller and a maximum power point tracker (MPPT) and a Q-profile unit according to [44-48] The high-level configuration of the PV system can be modified by the user and the PV system is able to provide voltagereactive power support into the grid during voltage sag events.
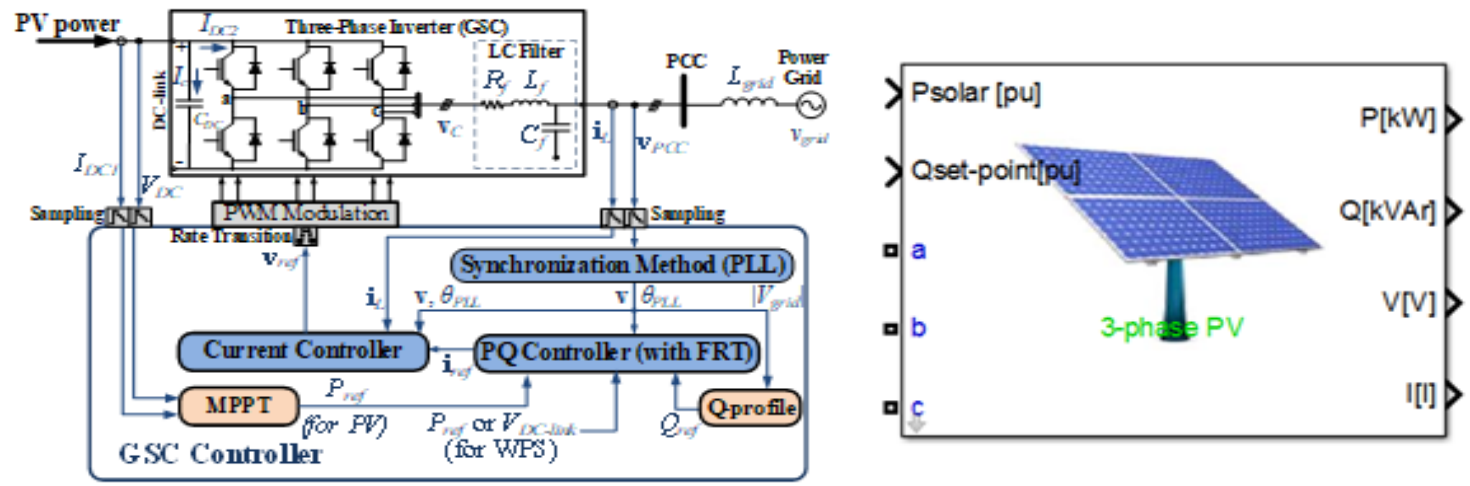

Figure 7. PV system model

\subsection{Battery energy storage system model}

The battery energy storage system (BESS) model is designed in a similar way with the PV model [44-46], it contains a grid-tied inverter with 3-wire interconnection while the charging and discharging rate $(\mathrm{kW})$ depend on the rating of the inverter and the characteristics of the storage device. There are two ways for 
managing the ESS. The first option is to allow the BESS to autonomously schedule it operation during a day in order to maximize its profit considering a variable pricing scheme Figure 8 . The second option is to externally manage the scheduling of the BESS by set-point send by an external controller which considers maximizing the self-consumption of the microgrid. It should be noted that the BESS has been designed in a way it optionally provide reactive power support during voltage sag.
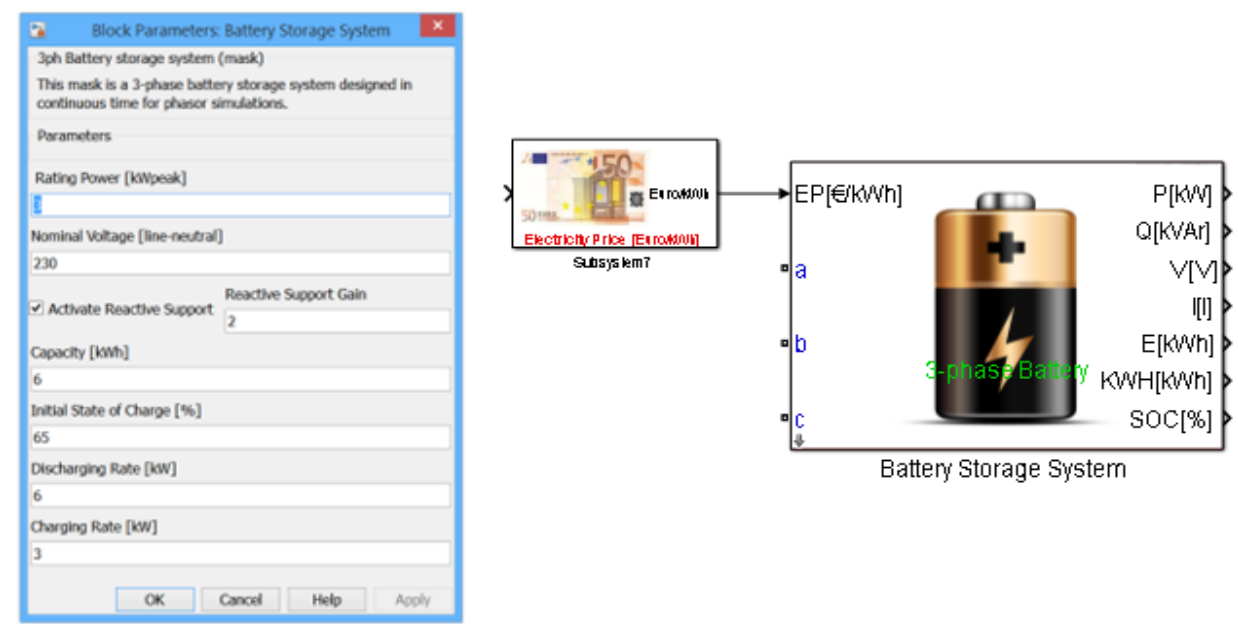

Figure 8 . Battery energy storage system (BESS) block

\subsection{Diesel generator model}

Diesel generator is actually one of the most important components of the microgrid, since it will operate as the master in case of islanding. The generator is simulated based on the sixth-order state space model. For the stable and controllable operation of the microgrid, the diesel generator is equipped with local controllers and more specifically, an AC5A exciter and a speed regulator based on the isochronous governor model. Figure 9 illustrates the diesel engine model [44-46]. Furthermore, the governor controller is constructed to able to change the generator's active power output according to set points, which canderive from the microgrid central controller for a proper energy scheduling during the interconnected mode.

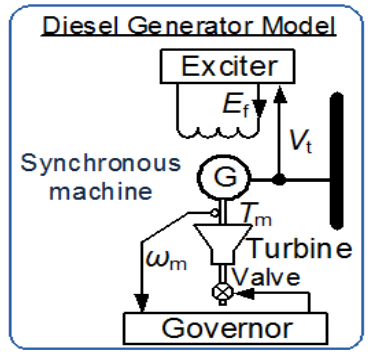

(a)

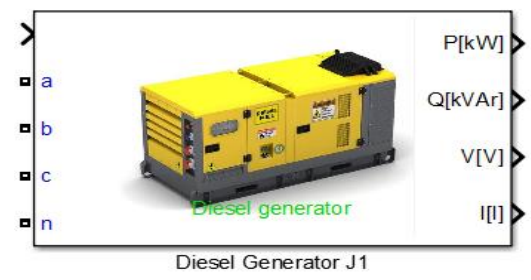

(c)

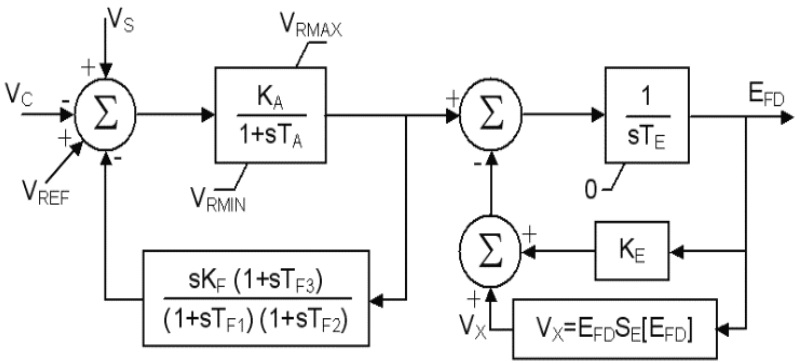

(b)

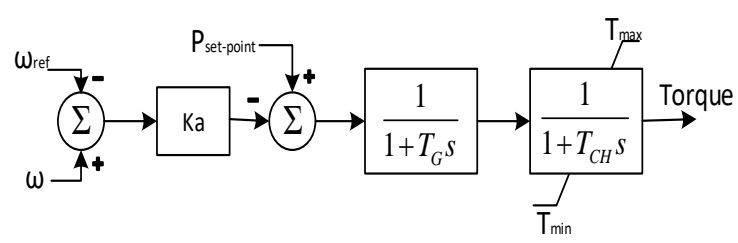

(d)

Figure 9. (a) Model of the diesel generator, (b) exciter AC5A, and (c) speed regulator model 


\subsection{Complete model of microrids MCAST and GJU}

After implementing all these microgrid systems components models, the models are combined together to form a complete MCAST and GJU microgrid system with grid connected and islanded. On the complete model of MCAST microgrid we have one renewable energy source are included two PVs system model installed in building D and F and one in building $\mathrm{J}$ with a $63.24 \mathrm{kWp}$ total energy generation. We have also one BESS and diesel generator on building D and F and one diesel generator on building. Loads are based on the active and reactive power data provided by MCAST [40, 49].

On the complete model of GJU microgrid we have also one renewable energy source are included one PV system model installed in buildings (B,D,E,F) with a $320 \mathrm{kWp}$ total energy generation. We have one battery storage system in buildings (B,C,D) and 6 diesel generators one in each building. Loads are the active and reactive power data provided by GJU [43]. Simulation of the system using the MATLAB/Simulink tool [44-46], the powers measurements are displayed and observed as explained in the real-time digital simulation in Section 5.

\section{REAL TIME SIMULATION}

The objective of the real-time simulator is to test the different electrical equipment in the most natural possible conditions: as if they were connected to the real physical systems associated with them. Therefore, the real-time simulator must reproduce as closely as possible the dynamic behavior of the electrical system under control [36]. The real-time digital simulation of the electrical system to be controlled passes through different phases:

a) A modeling phase that consists in the putting of equation of the system.

b) Design an algorithmic specification (choice of sampling period, discretization and quantification).

c) Finally, a phase of real - time implantation.

\subsection{Hardware and software architecture}

The hardware equipment installed in our SCAMRE laboratory consists of two connected simulators, the wanda-4u and the OP-5600 as shown in Figure 10. The wanda-4u target has two CPU processors including 2 enabled cores and $16 \mathrm{I} / \mathrm{Os}$, and two CPUs including 2 enabled cores and $16 \mathrm{I} / \mathrm{Os}$, for the OP5600. The main role of the target is the execution of different computation subsystems. The computation subsystem will be executed in real-time (or accelerated simulation mode) on a CPU core of the real-time target. The development, editing, verification and compilation of models are done on the host computer. Its second mission is to function as a console or command post in charge of control and observation during the simulation. Ethernet protocol is used to communicate between hosts and targets. The data between computation subsystem and GUI subsystem is exchanged asynchronously through the TCP / IP link.

All models studied are modeled and developed in the Matlab/Simulink environment. RT-LAB is a graphic platform that allows making 4 main processes: edit models under Simulink directly via RT-LAB, compile (consist to transform Simulink model into a real time application), load and execute the digital simulation on the real-time targets.

Multi-processor operating mode enables real-time simulations on RT-LAB platform. The overall purpose is to separate a complex system to some simple subsystems and do parallel operations in multiprocessor. RT-LAB connects physical devices to the simulation system to make the simulation closer to reality and get more realistic results $[50,51]$.

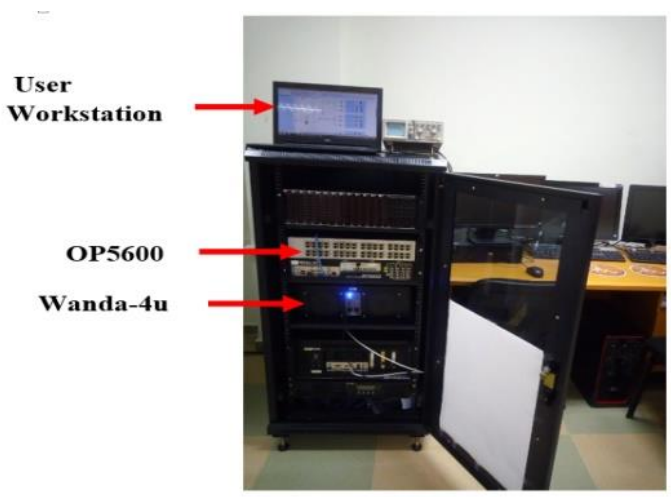

Figure 10. RT-LAB simulator architecture (SCAMRE Laboratory) 


\section{IMPLEMENTATION, RESULTS AND DISCUSSION}

For better visibility of the projects presented, it is mandatory to realize a microgrid model and to simulate it in real-time with the eMEGAsim software. For this reason, the entire model has to be rearranged mainly into two or three subsystems, which are master, slave and console subsystems. The microgrid system is modeled in an environment that integrates Simulink/SimPowerSystems with the eMEGAsim simulation of the RT LAB platform. This platform improves the simulation of significantly large systems with real-time performance across multiple CPUs.

\subsection{MCAST microgrid pilot and scenarios}

Before moving on to real-time digital simulation, we first start by separating the model into 2 subsystems (SM_MCAST and SC_Monitoring) to distinguish the computation subsystem from the GUI subsystem and to assign the first subsystem to CPU core, as depicted in Figure 11. The OpComm block ensures communication between the two subsystems (computation and GUI).All subsystems inputs must first go through an OpComm block before any operations can be done on the signals they are associated with. We used the OpWrite File block from the RT-LAB library to record Simulink signals and data in a MAT file using a Mux block. Figure 12 show the compelte system architecture.

\section{RT-LAB MCAST MODEL}

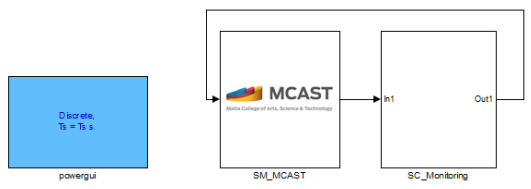

Figure 11. MCAST microgrid model in RT-LAB platform

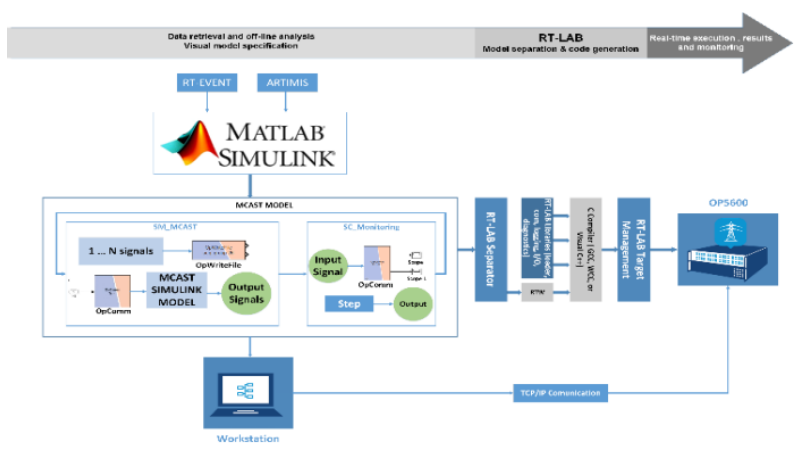

Figure 12. MCAST system architecture in RT-LAB platform with OpComm and OpWriteFile blocks

\subsubsection{Scenarios, results and discussion}

In order to test the correct operation of the microgrid MCAST that we model, we realized three different simulation scenarios in real time with $50 \mu$ s step simulation. For the first scenario, a simulation of one-hour duration under normal conditions in grid-connected mode is performed. The data corresponds to a period of one hour, from 8:00 am to 9:00 am, of the 13/07/2017 representing a high-load period as shown in Figures 13 and 14.

For the second scenario, the same data is used. Now, the power from the grid is interrupted during 15 minutes (islanded operation). Finally, the last scenario corresponds to an evening period, from 19:50 pm to 20:50 pm of the same day as shown in Figures 13 and 15.

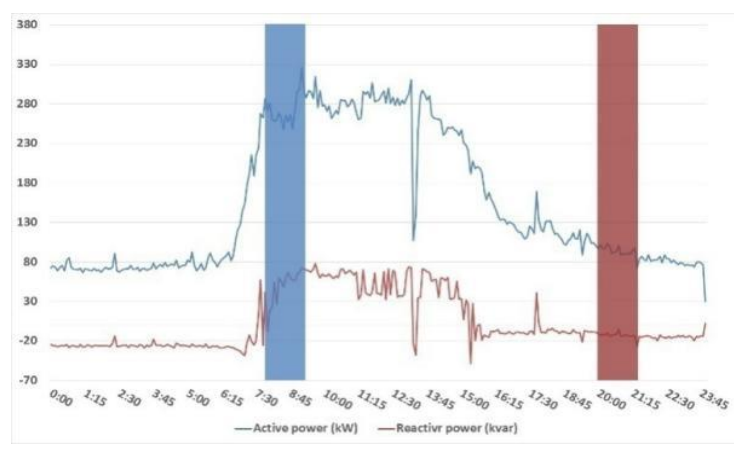

Figure 13. Active and reactive power data in $24 \mathrm{~h}$

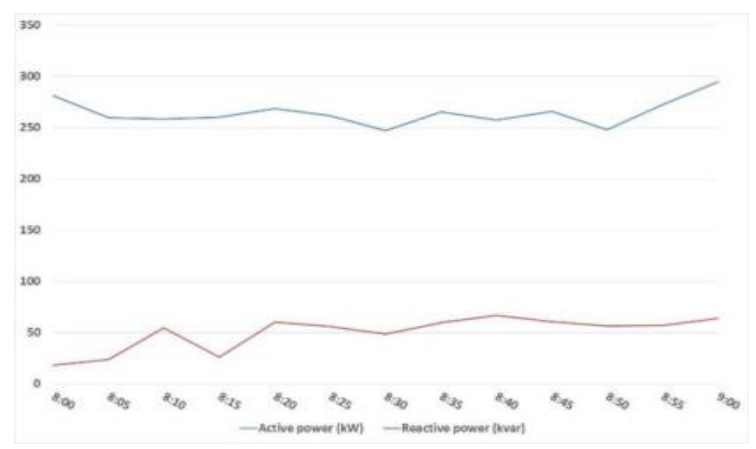

Figure 14. Active and reactive power data from 8:00 am to 9:00 am 


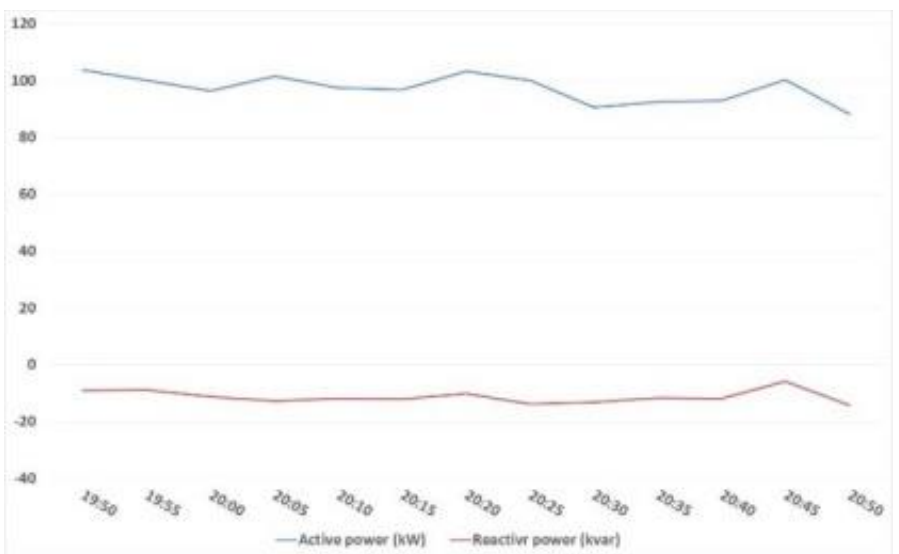

Figure 15. Active and reactive power data from $19: 50 \mathrm{pm}$ to $20: 50 \mathrm{pm}$

\section{MCAST Scenario 1}

The results of the first scenario of the real-time digital simulation are shown in Figure 16 and Figure 17. The first figure is divided into eight illustrations that represent active (a) and reactive (b) power generated (grid, PVs, diesel generators), active (c) and reactive (d) powers of loads, active battery power (e), battery SoC (f), solar irradiance (g) and temperature (h) data respectively. The second figure represents load voltage and current profile during the real-time digital simulation.

From 0 s to 3600 s we see that the active and reactive power generated is proportional to the loads (the power generated is greater than the building loads because in the model we have other constant loads). $80 \%$ of the energy produced comes from the grid and the rest of $20 \%$ is generated by the PVs. The power generated by the grid is between $220 \mathrm{~kW}$ and $270 \mathrm{~kW}$, and the power produced by the PVs is between $48 \mathrm{~kW}$ and $50 \mathrm{~kW}$, the power generated by the diesel generator is $0 \mathrm{~kW}$ given the fact that the microgrid is constantly in grid-connected mode. The diesel generation is expected to start when there is a power failure in the grid and the microgrid operates in islanded mode. From $0 \mathrm{~s}$ to $2400 \mathrm{~s}$ the battery is on charging mode and the state of charge is between $65 \%$ and $95 \%$.

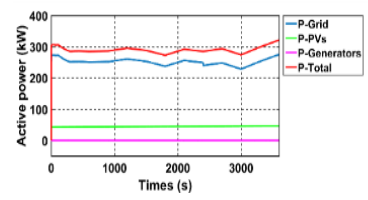

(a)

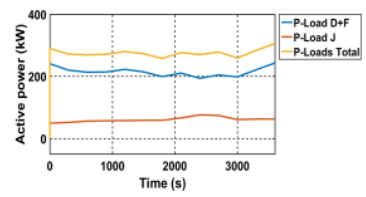

(c)

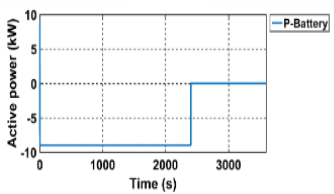

(e)

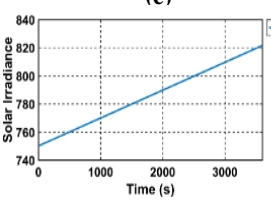

(g)

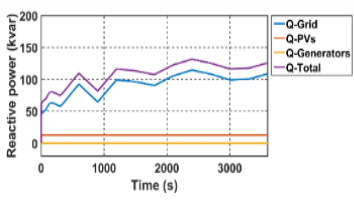

(b)

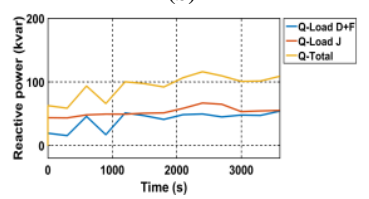

(d)

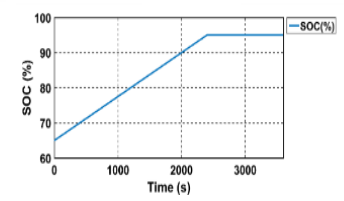

(f)

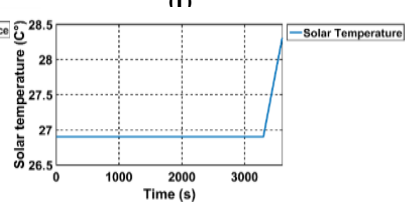

(h)

Figure 16. Results of MCAST real-time digital simulation (Scenario1)
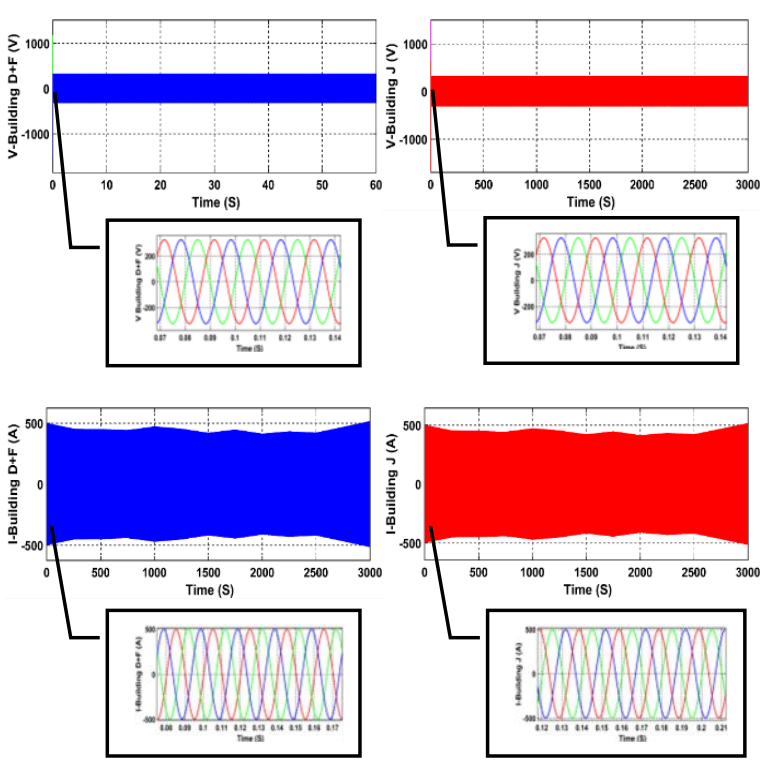

Figure 17. V and I load results of MCAST real-time digital simulation (scenario1) 


\section{MCAST Scenario 2}

The results of the second scenario of the real-time digital simulation are shown in Figure 18 and are divided into six illustrations that represent total active and reactive power generated (grid, PVs, diesel generators) (a,b,c,d,e,f) respectively. According to the case. From 0 s to 3600 s, we see that the total active and reactive power generated is proportional to the loads. At $1800 \mathrm{~s}$, the power grid is interrupted, we see that the power generated by the grid becomes $0 \mathrm{~kW}$ and the diesel generator takes the role of producing the power to ensure the continuity of production. At 2700s, the power grid is restored, the power generated by the diesel generator becomes $0 \mathrm{~kW}$, the grid becomes again the master energy source. We conclude that the diesel generator becomes the master in the case of islanding mode.

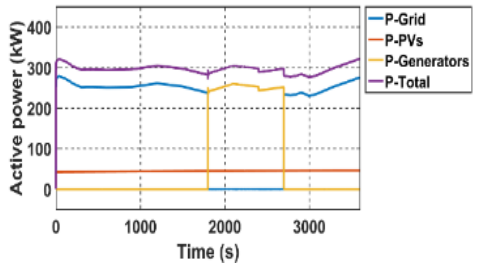

(a)

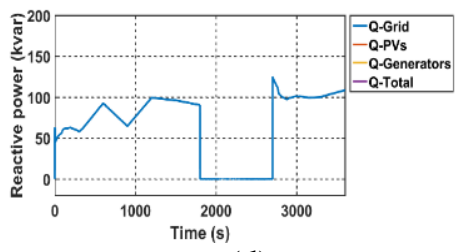

(d)

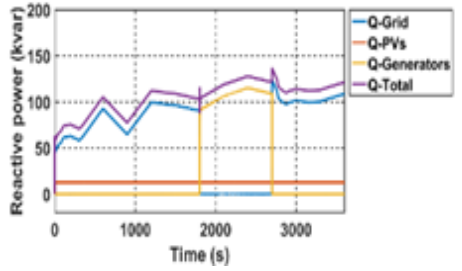

(b)

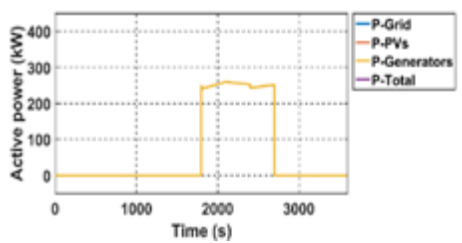

(e)

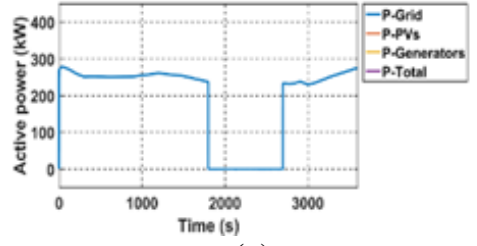

(c)

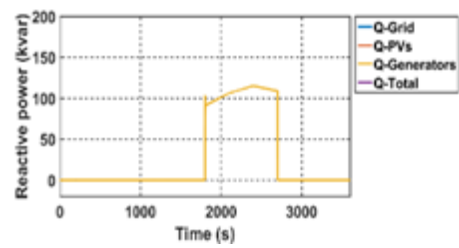

(f)

Figure 18. Results of MCAST Real-time digital simulation (scenario 2)

\section{MCAST Scenario 3}

The results of the third scenario of the real-time digital simulation are shown in Figure 19 and are divided also into six illustrations that represent total active (a) and reactive (b) power generated (grid, PVs, diesel generators), active (c) and reactive (d) power loads and solar irradiance (e) and temperature (f) data respectively.

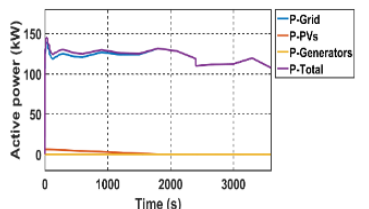

(a

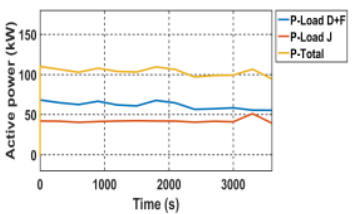

(c)

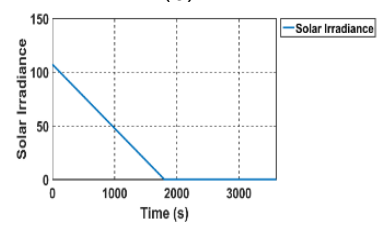

(e)

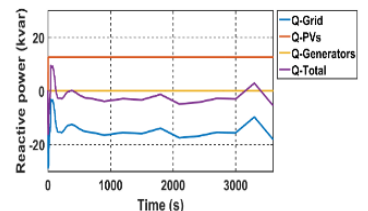

(b)

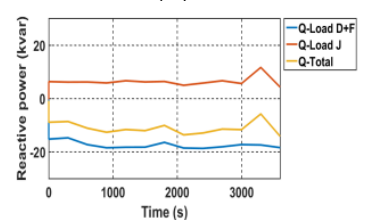

(d)

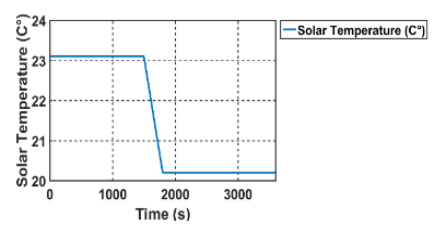

(f)

Figure 19. Results of MCAST real-time digital simulation (Scenario3) 
From 0 to $3600 \mathrm{~s}$ we see that the total active and reactive power generated is proportional to the night loads. From 0 s to 1700 s the power generated by the PVs decreases from $5 \mathrm{~kW}$ to $0 \mathrm{~kW}$ and it represents $2 \%$ of the total production of the power. The solar irradiance decreases from $108 \mathrm{~W} / \mathrm{m} 2$ to $0 \mathrm{~W} / \mathrm{m} 2$. The temperature also decreases from $23,1 \mathrm{oC}$ to $20,1 \mathrm{oC}$. At 1700 s grid represents $100 \%$ of the total production of power.

\subsection{GJU microgrid pilot and scenarios}

Before proceeding to the real-time digital simulation of the GJU model, the same procedure was followed in the same way as the MCAST model as shown in Figure 20. An OpComm block was added to provide communication between the computation subsystem and the GUI subsystem. We also used the OpWriteFile block of the RT LAB library to record Simulink signals and data into a MAT file using a Mux block, Figure 21 show the complete GJU System Architecture in RT-LAB for the real-time digital simulation.

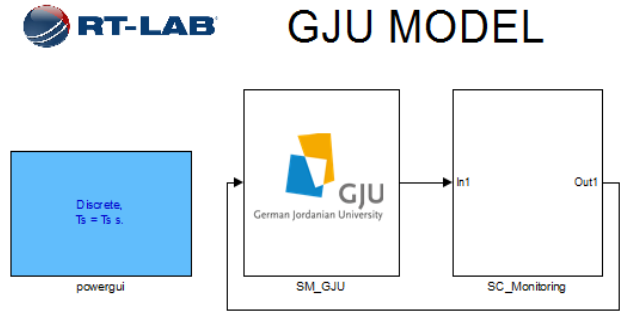

Figure 20. GJU model in RT-LAB platform

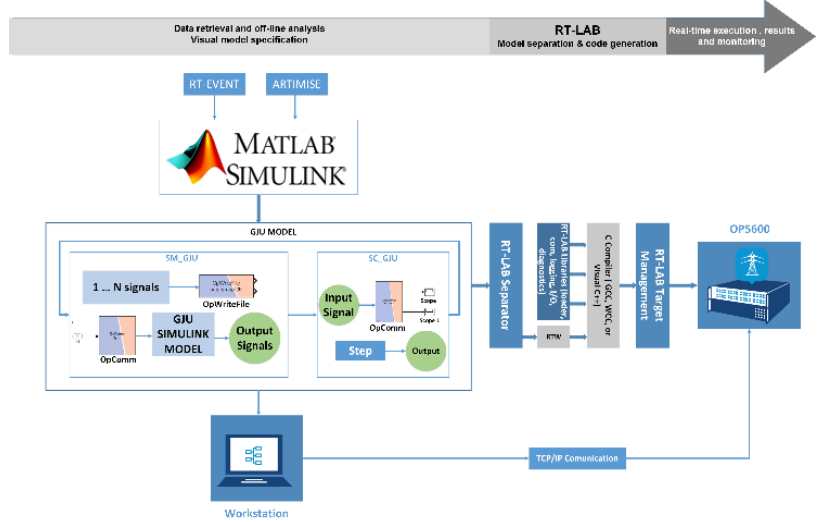

Figure 21. GJU system architecture with OpComm and OpWriteFile block

\subsubsection{Scenarios, results and discussion}

To test the good operation of the modelled GJU microgrid, 3 different simulation scenarios were realized in real-time with $50 \mu$ s step simulation. For the first scenario we have simulated a one hour duration under normal grid-connected conditions (morning); the data selected for this simulation include a timeframe from 10:00 am to 11:00 am of the 10/07/2017, representing the period where the load is very high as shown in Figure 22. For the second scenario we used the same data as the previous scenario but with different conditions, where the power from the grid has been uninterrupted for a period of 18 minutes (islanded operation). For the last scenario we proceeded in the same way as the first scenario but with data from 16:30 pm to 17:30 pm of the same date, representing the sunset moment as shown in Figure 23.

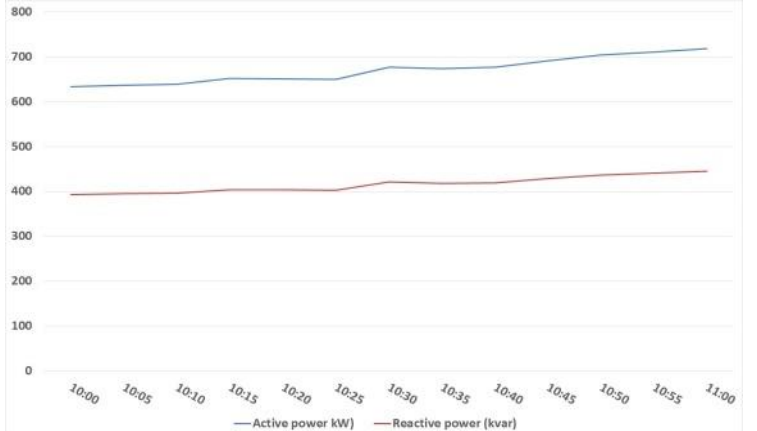

Figure 22. Active and reactive power data from 10:00 am to 11:00 am

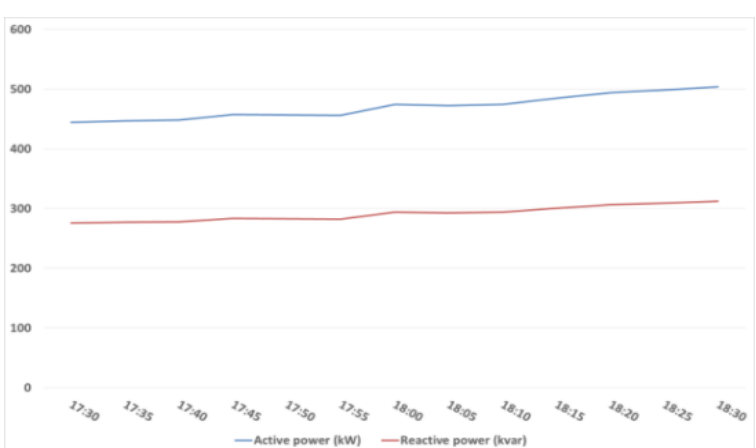

Figure 23. Active and reactive Power data from 17:30 pm to $18: 30 \mathrm{pm}$ 


\section{GJU Scenario 1}

The results of the first scenario of the real-time digital simulation are shown in Figures 24 and 25 . The first figure is divided into eight illustrations that represent active (a) and reactive (b) power (grid, PVs, diesel generator), active (c) and reactive (d) power of loads, active battery power (e), battery SoC (f), solar irradiance $(\mathrm{g})$ and temperature $(\mathrm{h})$ data, respectively.
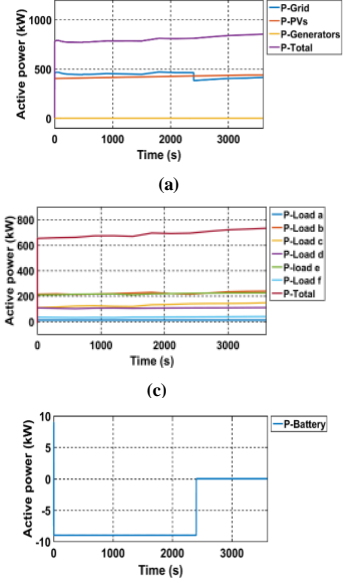

(e)

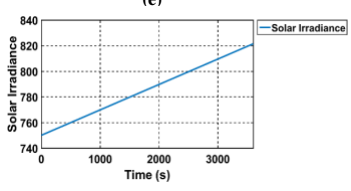

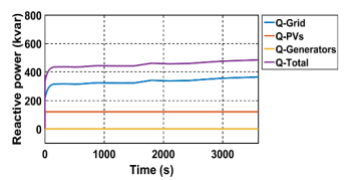

(b)

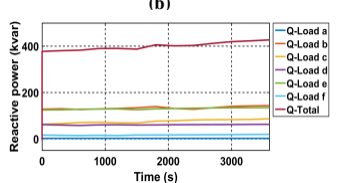

(d)
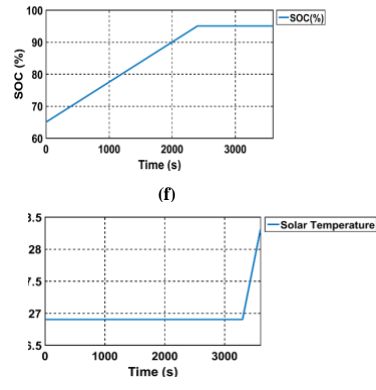

Figure 24. Active power, reactive power, SOC, solar irradiance and temperature results of GJU real-time digital simulation
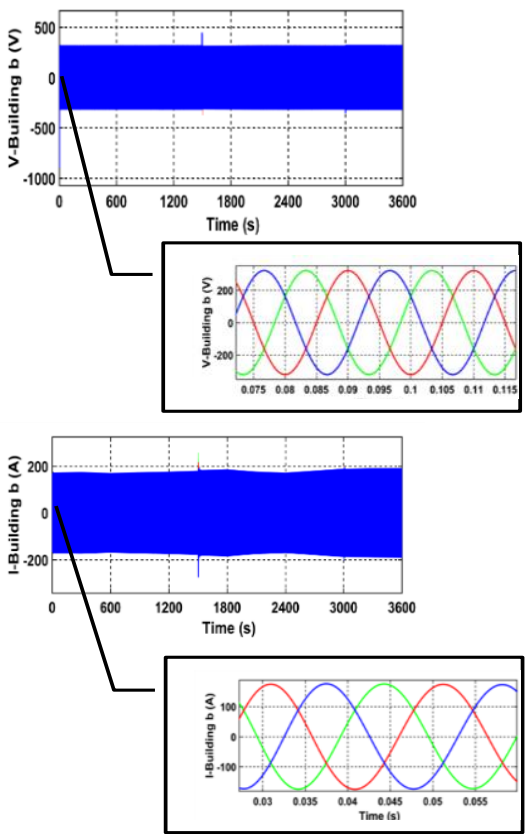

Figure 25. V and I load results of GJU real-time digital simulation (scenario 1)

\section{GJU Scenario 2}

The results of the second scenario of the real-time digital simulation are shown in Figure 26 and are divided into six illustrations that represent different outputs show (a,b,c,d,e,f) total active and reactive power (grid,PVs, diesel generator).

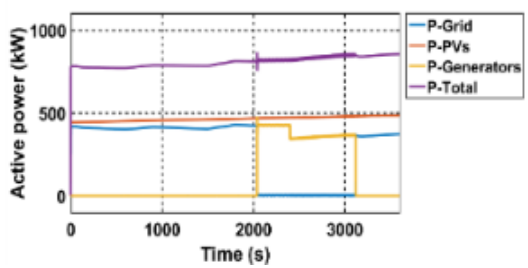

(a)

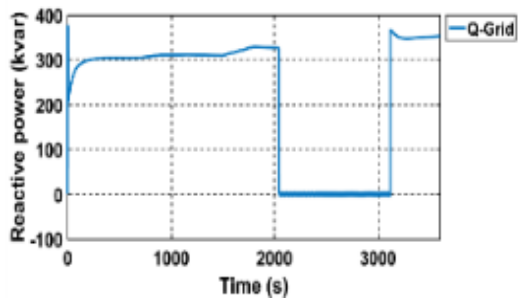

(d)

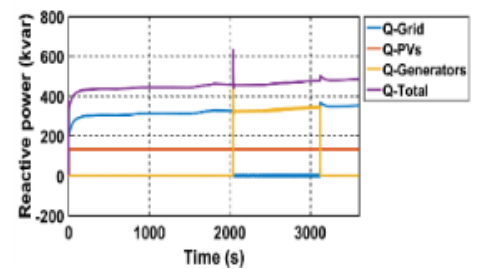

(b)

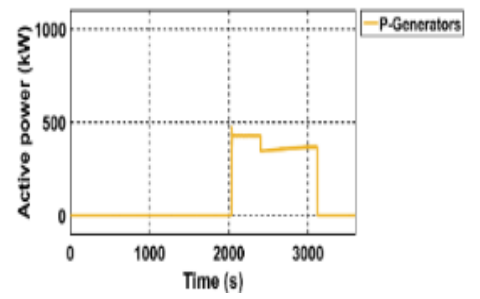

(e)

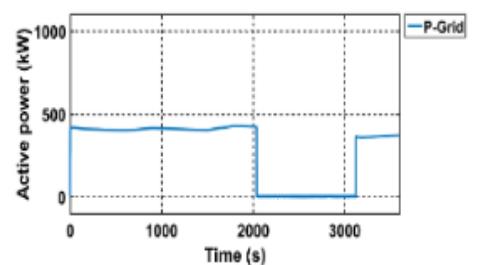

(c)

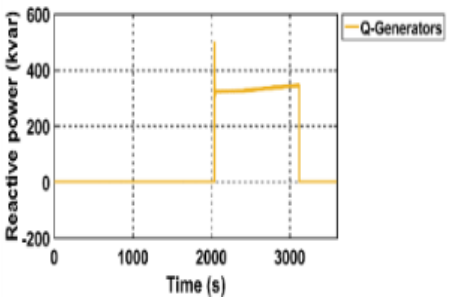

(f)

Figure 26. Active and reactive power results of GJU real-time digital simulation 
From 0s to $3600 \mathrm{~s}$ we see that the total active and reactive power generated is proportional to the loads. At 2040 s we disconnect the grid using a 3 phase breaker, we observe that the power generated by the grid becomes $0 \mathrm{~kW}$ and the diesel generator breaker closes and takes the role of producing the power to ensure the continuity of production. At $3150 \mathrm{~s}$ we connect the grid, we see that the 3 phase breaker of diesel generator opens and the power generated becomes $0 \mathrm{~kW}$, the grid becomes master. We conclude that the diesel generator becomes the master in case of islanding mode.

\section{GJU Scenario 3}

The results of the third scenario of the real-time digital simulation are shown in Figure 27 and it divided also into six illustrations that represent different outputs show (a,b,c,d,e,f), represent respectively, total active and reactive generated power (grid, PVs, Diesel generator), active and reactive power loads, solar irradiance and temperature data.

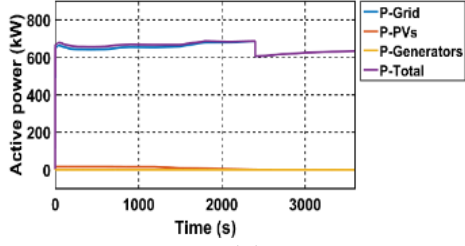

(a)

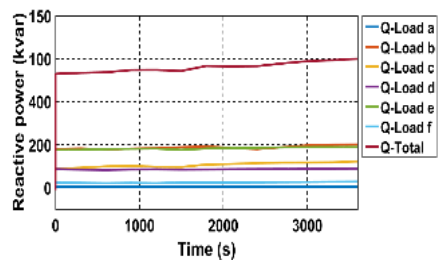

(d)

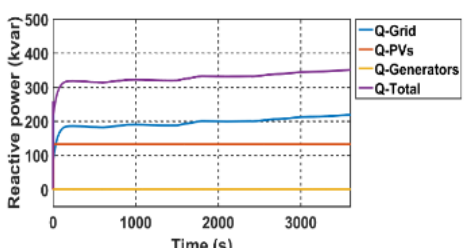

(b)

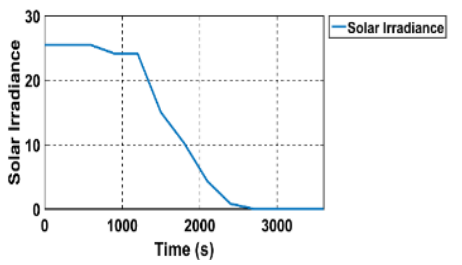

(e)

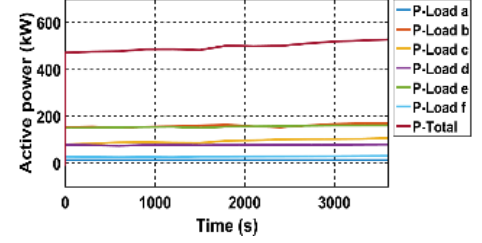

(c)

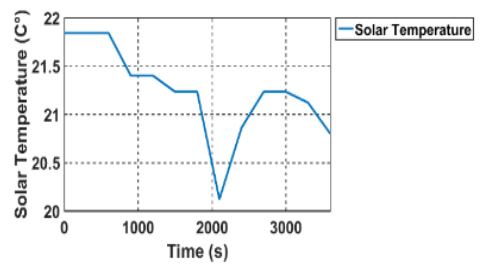

(f)

Figure 27. Active power, reactive power, SOC, solar irradiance and temperature results of MCAST real-time digital simulation (Scenario3)

From 0 s to 3600 s we see that the total active and reactive power generated is proportional to the night loads. From 0 s to 2400 s the power generated by the PVs decreases from $10 \mathrm{~kW}$ to $0 \mathrm{~kW}$ and it represents $1 \%$ of the total production of the power. The solar irradiance decreases from $26 \mathrm{~W} / \mathrm{m} 2$ to $0 \mathrm{~W} / \mathrm{m} 2$. The temperature also decreases from 21,8 oC to 20,2 0C. At 2400 s grid represents $100 \%$ of the total production of power.

\section{CONCLUSION}

In this paper two microgrid models have been designed based on actual premises of two university campus in Malta (MCAST) and Jordan (GJU) using RT-LAB platform. One-hour real time digital simulation is performed using the OP5600 simulator. Three different scenarios are evaluated for each model and the results are satisfying for both the MCAST and GJU pilots.

The real-time digital simulation on RT-LAB platform allowed us to study several scenarios in very close to reality conditions, and to make several tests on the models conceived without risk, before deploying them in the field. The results obtained have validated the proper functioning of the electrical energy management in the two future microgrids to be realized. The validation was obtained thanks to the real time digital simulation capable of performing calculations at a time step of up to $10 \mu \mathrm{s}$.

Future work can be directed towards the optimization, analysis and decentralized control of microgrids that would involve different energy management strategies. The optimization aims to reduce the current loads present in buildings as well as to optimize the use of current renewable generation systems. However, in order to be able to evaluate simulation results, both optimization and control must be synchronized with real-time data to be able to monitor the current situation in buildings. We can then make HIL simulation using real sources of electrical power and real energy sources equipment to validate the final design and move directly to field deployment. Efficient energy management and the integration of RES while providing a laboratory concept, can adapt microgrids to the real state in the future. 


\section{ACKNOWLEDGEMENTS}

The authors wish to thank for their collaboration, all the researchers of "3DMicroGrid " through the ERANETMED initiative of Member States, Associated Countries and Mediterranean Partner Countries (3DMgrid Project ID eranetmed_energy-11-286).

\section{REFERENCES}

[1] N. Hatziargyriou, H. Asano, R. Iravani, and C. Marnay, "Microgrids," IEEE Power \& Energy Magazine, vol. 5, pp. 78-94, Jul-Aug 2007.

[2] E. Bullich-Massague, F. Diaz-Gonzalez, M. Aragues-Penalba, F. Girbau-Llistuella, P. Olivella-Rosell, and A. Sumper, "Microgrid clustering architectures," Applied Energy, vol. 212, pp. 340-361, Feb 152018.

[3] S. K. Sahoo, A. K. Sinha, and N. K. Kishore, "Control Techniques in AC, DC, and Hybrid AC-DC Microgrid: Review," IEEE Journal of Emerging and Selected Topics in Power Electronics, vol. 6, pp. 738-759, Jun 2018.

[4] J. M. Guerrero, M. Chandorkar, T. L. Lee, and P. C. Loh, "Advanced Control Architectures for Intelligent Microgrids-Part I: Decentralized and Hierarchical Control," IEEE Transactions on Industrial Electronics, vol. 60, pp. 1254-1262, Apr 2013.

[5] J. J. Justo, F. Mwasilu, J. Lee, and J. W. Jung, "AC-microgrids versus DC-microgrids with distributed energy resources: A review," Renewable \& Sustainable Energy Reviews, vol. 24, pp. 387-405, Aug 2013.

[6] A. T. Elsayed, A. A. Mohamed, and O. A. Mohammed, "DC microgrids and distribution systems: An overview," Electric Power Systems Research, vol. 119, pp. 407-417, Feb 2015.

[7] D. Kumar, F. Zare, and A. Ghosh, "DC Microgrid Technology: System Architectures, AC Grid Interfaces, Grounding Schemes, Power Quality, Communication Networks, Applications, and Standardizations Aspects," IEEE Access, vol. 5, pp. 12230-12256, 2017.

[8] E. Unamuno and J. A. Barrena, "Hybrid ac/dc microgrids-Part I: Review and classification of topologies," Renewable \& Sustainable Energy Reviews, vol. 52, pp. 1251-1259, Dec 2015.

[9] P. Wang, X. Liu, C. Jin, P. Loh, and F. Choo, "A Hybrid AC/DC Micro-Grid Architecture, Operation and Control," 2011 IEEE Power and Energy Society General Meeting, 2011.

[10] M. F. Zia, E. Elbouchikhi, and M. Benbouzid, "Microgrids energy management systems: A critical review on methods, solutions, and prospects," Applied Energy, vol. 222, pp. 1033-1055, 2018.

[11] W. Su and J. Wang, "Energy Management Systems in MicrogridOperations " The Electricity Journal, vol. 25, pp. 45-60, 2012.

[12] Y. W. Li and F. Nejabatkhah, "Overview of control, integration and energy management of microgrids," Journal of Modern Power Systems and Clean Energy, vol. 2, pp. 212-222, Sep 2014.

[13] L. X. Meng, E. R. Sanseverino, A. Luna, T. Dragicevic, J. C. Vasquez, and J. M. Guerrero, "Microgrid supervisory controllers and energy management systems: A literature review," Renewable \& Sustainable Energy Reviews, vol. 60, pp. 1263-1273, Jul 2016.

[14] A. Kaur, J. Kaushal, and P. Basak, "A review on microgrid central controller," Renewable \&Sustainable Energy Reviews, vol. 55, pp. 338-345, Mar 2016.

[15] D. E. Olivares, C. A. Canizares, and M. Kazerani, "A Centralized Energy Management System for Isolated Microgrids," IEEE Transactions on Smart Grid, vol. 5, pp. 1864-1875, Jul 2014.

[16] D. E. Olivares, C. A. Canizares, and M. Kazerani, "A Centralized Optimal Energy Management System for Microgrids," 2011 IEEE Power and Energy Society General Meeting, 2011.

[17] D. E. Olivares, J. D. Lara, C. A. Canizares, and M. Kazerani, "Stochastic-Predictive Energy Management System for Isolated Microgrids," IEEE Transactions on Smart Grid, vol. 6, pp. 2681-2693, Nov 2015.

[18] M. R. B. Khan, R. Jidin, and J. Pasupuleti, "Multi-agent based distributed control architecture for microgrid energy management and optimization," Energy Conversion and Management, vol. 112, pp. 288-307, Mar 152016.

[19] C. S. Karavas, G. Kyriakarakos, K. G. Arvanitis, and G. Papadakis, "A multi-agent decentralized energy management system based. on distributed intelligence for the design and control of autonomous polygenerationmicrogrids," Energy Conversion and Management, vol. 103, pp. 166-179, Oct 2015.

[20] B. Zhao, M. D. Xue, X. S. Zhang, C. S. Wang, and J. H. Zhao, "An MAS based energy management system for a stand-alone microgrid at high altitude," Applied Energy, vol. 143, pp. 251-261, Apr 12015.

[21] V. N. Coelho, M. W. Cohen, I. M. Coelho, N. Liu, and F. G. Guimaraes, "Multi-agent systems applied for energy systems integration: State-of-the-art applications and trends in microgrids," Applied Energy, vol. 187, pp. 820-832, Feb 12017.

[22] A. Hirsch, Y. Parag, and J. Guerrero, "Microgrids: A review of technologies, key drivers, and outstanding issues," Renewable and Sustainable Energy Reviews, vol. 90, pp. 402-411, 2018.

[23] M. Soshinskaya, W. H. J. Crijns-Graus, J. M. Guerrero, and J. C. Vasquez, "Microgrids: Experiences, barriers and success factors," Renewable \& Sustainable Energy Reviews, vol. 40, pp. 659-672, Dec 2014.

[24] A. Gaviano, K. Weber, and C. Dirmeier, "Challenges and Integration of PV and Wind Energy Facilities from a Smart Grid Point of View," Pv Asia Pacific Conference 2011, vol. 25, pp. 118-125, 2012.

[25] R. Zamora and A. K. Srivastava, "Controls for microgrids with storage: Review, challenges, and research needs," Renewable \& Sustainable Energy Reviews, vol. 14, pp. 2009-2018, Sep 2010.

[26] W. I. Bower, D. T. Ton, R. Guttromson, S. F. Glover, J. E. Stamp, D. Bhatnagar, and J. Reilly, "The Advanced Microgrid: Integration and Interoperability," Sandia National Lab. SAND2014-1535, 2014. 
[27] S. Mirsaeidi, D. M. Said, M. W. Mustafa, M. H. Habibuddin, and K. Ghaffari, "Progress and problems in microgrid protection schemes," Renewable \&Sustainable Energy Reviews, vol. 37, pp. 834-839, Sep 2014.

[28] L. Che, M. E. Khodayar, and M. Shahidehpour, "Adaptive Protection System for Microgrids: Protection practices of a functional microgrid system," IEEE Electrification Magazine, vol. 2, pp. 66-80, 2014.

[29] P. Basak, S. Chowdhury, S. H. N. Dey, and S. P. Chowdhury, "A literature review on integration of distributed energy resources in the perspective of control, protection and stability of microgrid," Renewable \& Sustainable Energy Reviews, vol. 16, pp. 5545-5556, Oct 2012.

[30] 3DMicroGrid.Available:http://www.3dmicrogrid.com/ project number: ERANETMED_ENERG - 11 - 286 (20172019).

[31] B. J. Brearley and R. R. Prabu, "A review on issues and approaches for microgrid protection," Renewable \& Sustainable Energy Reviews, vol. 67, pp. 988-997, Jan 2017.

[32] "Power Hardware in the loop Simulation," RTDS Technologies.

[33] C. S. Edrington, M. Steurer, J. Langston, T. El-Mezyani, and K. Schoder, "Role of Power Hardware in the Loop in Modeling and Simulation for Experimentation in Power and Energy Systems," Proceedings of the Ieee, vol. 103, pp. 2401-2409, Dec 2015.

[34] M. D. O. Faruque, T. Strasser, G. Lauss, V. Jalili-Marandi, P. Forsyth, C. Dufour, V. Dinavahi, A. Monti, P. Kotsampopoulos, J. A. Martinez, K. Strunz, M. Saeedifard, X. Wang, D. Shearer, M. Paolone, R. Brandl, M. Matar, A. Davoudi, and R. Iravani, "Real-time digital simulation Technologies for Power Systems Design, Testing, and Analysis," IEEE Power and Energy Technology Systems Journal, vol. 2, pp. 63-73, 2015.

[35] A. S. Vijay, S. Doolla, and M. C. Chandorkar, "Real-Time Testing Approaches for Microgrids," IEEE Journal of Emerging and Selected Topics in Power Electronics, vol. 5, pp. 1356-1376, Sep 2017.

[36] OPAL-RT. Available: https://www.opal-rt.com/

[37] RTDS. Available: https://www.rtds.com/

[38] Typhoon HIL. Available: https://www.typhoon-hil.com/

[39] National Instruments. Available: http://sine.ni.com/nips/cds/view/p/lang/en/nid/207301

[40] Brian Azzopardi, Stefan Azzopardi, Renata Mikalauskiene, Al-Agtash Salem, LenosHadjidemetriou, DimitrisTzovaras, Francisco de Paula Garcia Lopez, Petra Brandl, Ahmet Onen, Nicholas Borg, Mounir Khiat, Tim Camilleri "Design considerations for campus micro-grid: MCAST Case Study" in The World Conference on PhotovoltaicEnergy Conversion (WCPEC-7), June 2018, Hawaii.

[41] A. D. Bintoudi1, L. Zyglakis1, T. Apostolos1, D. Ioannidis1, S. Al-Agtash, J. L. Martinez Ramos, A. Onen, B. Azzopardi, L. Hadjidemetriou, N. Martensen, C. Demoulias, D. Tzovaras, "Novel Hybrid Design for Microgrid Control,“ in Asia-Pacific Power and Energy Engineering Conference (APPEEC), 2017 IEEE PES, DOI: 10.1109/APPEEC.2017.8308958.

[42] N. Martensen, T. Ackermann, S. Al-Agtash, H. AbdelHafez, B. Azzopardi, R. Mikalauskiene, D. Tzovaras, D. Ioannidis, A. Onen, Y. Yoldas, A. Marano, J. L. Martinez-Ramos, M. Khiat, L. Hadjidemetriou, E. Kyriakides, T. Camilleri, N. Borg, "Framework Design for Smart Micro-Grids," in The 3rd International Hybrid Power Systems Workshop,2018.[Online].Available: http://hybridpowersystems.org/wpcontent/uploads/sites/9/2018/05/7B_1_TENE18_047_paper_Martensen_Nis.pdf

[43] C. Al-hashem, S. Al Agtash, "GJU MicroGrid-Data and GJUmicrogrid description”, 2017.

[44] L. Hadjidemetriou, E. Kyriakides and F. Blaabjerg, "A robust synchronization to enhance the power quality of renewable energy systems," IEEE Trans. Industrial Electronics, vol. 62, no. 8, pp. 4858-4868, Aug. 2015.

[45] L. Hadjidemetriou, E. Kyriakides and F. Blaabjerg, "An adaptive tuning mechanism for phase-locked loop algorithms for faster time performance of interconnected renewable energy sources," IEEE Trans. Industry Applications, vol. 51, no. 2, pp. 1792-1804, Apr. 2015.

[46] L. Hadjidemetriou, and E. Kyriakides, "Accurate and efficient modeling of grid tied inverters for investigating their interaction with the power grid," in Proc. IEEE POWERTECH, Manchester, UK, pp. 1-6, 2017.

[47] M. Isha, Shirbhate, S. Sunita Barve, "Solar panel monitoring and energy prediction for smart solar system" International Journal of Advances in Applied Sciences (IJAAS), vol. 8, no. 2, pp. 136-142, June 2019.

[48] G. Sureshkumaar, N. Kannan, S. Thomas, "MATLAB/SIMULINK based simulations of KY converter for PV panels powered led lighting system", International Journal of Power Electronics and Drive System (IJPEDS), vol. 10, no. 4, pp. 1885-1893, December 2019.

[49] L. Hadjidemetriou1, L. Zacharia1, E. Kyriakides1, B. Azzopardi, S. Azzopardi, R. Mikalauskiene, S. Al-Agtash, M. Al-hashem, A. Tsolakis, D. Ioannidis and D. Tzovaras“ Design Factors for Developing a University Campus Microgrid”, Energycon conference 2017. 978-1-5386-3669-5/18/\$31.00 @2018 IEEE.

[50] T.E.Somefun, C.O.A, Awosope, A.Chiagoro, "Smart prepaid energy metering system to detect energy theft with facility for real time monitoring", International Journal of Electrical and Computer Engineering (IJECE), vol. 9, no. 5, pp. 4184-4191, October 2019.

[51] L. Ghomri, M. Khiat, S. Khiat "Modeling and Real Time simulation of Microgrids in Algerian Sahara area", Energycon conference 2017. 978-1-5386-3669-5/18/\$31.00 @2018 IEEE. 


\section{BIOGRAPHIES OF AUTHORS}
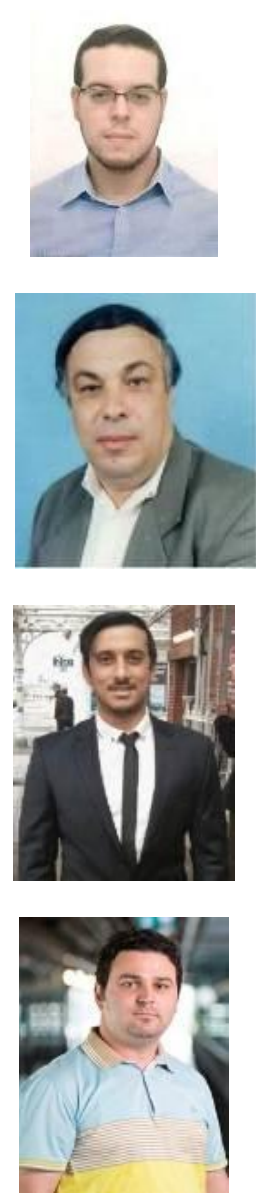

Sidahmed Khiat has received his M.S degree in Computer Engineer from University of Oran, Algeria, in 2016. He is currently a Ph.D student in the Electrical Engineering Department at ENPO-MA, Oran, Algeria and member of "SCAMRE" laboratory. His research activities include the control electric power systems, real time simulation of power systems, smart grids, smart microgrids and Computer Science.

Pr. Abdelkader Chaker is a Professor in the Electrical Engineering Department at ENPO-MA, Oran, Algeria and director of "SCAMRE" laboratory. He received a PHD degree in electrical engineering from Polytechnic Institute of Saint Petersburg Russia. His research activities include the stability, optimization and maintenance of electrical networks.

Lazaros Zacharia has received his Diploma in Electrical and Computer Engineer from National Technology University of Athens, Greece, in 2013. In 2014, he obtained the MSc in Sustainable Energy Futures with distinction from Imperial College, London. He is currently a Ph.D student in the Department of Electrical and Computer Engineering at the University of Cyprus and a Researcher at KIOS Research and Innovation Center of Excellence. His research interests lie in the areas of Wide Area Monitoring and Control, smart grids, electric power systems, state estimation in the transmission system and renewable energy.

Dr. Ahmed Onen received the B.Sc. degree in Electrical-Electronics Engineering from Gaziantep University in 2005. He received the M.S degree in Electrical-Computer Engineering from Clemson University in2010 and his Ph.D. from Virginia Tech - Electrical and Computer Engineering Department in 2014. Prior to joining Abdullah Gul University as a faculty of Electrical-Electronics Engineering in 2014, He was a member of EDD company located in US to develop software for distribution companies. He is in the editor board of Electrical Engineering (Springer), Frontiers in Energy, El-Cezeri Journal of Science and Engineering. 